\title{
Masonería en tiempos electorales: El fenómeno del Bronco y la antimasonería en Nuevo León, México (2015)
}

\author{
Freemasonry at election times: The phenomenon of Bronco and \\ anti- Masonry at Nuevo Leon, Mexico (2015)
}

\begin{abstract}
Eduardo Tzili Apango
Licenciado en Relaciones Internacionales por la Benemérita Universidad Autónoma de Puebla y Maestro en Estudios de Asia y África con especialidad en China por El Colegio de México. Miembro del equipo de la Dirección de Investigación de la Universidad Iberoamericana, Ciudad de México. Correo electrónico: e.tzili.a@gmail.com
\end{abstract}

DOI: http://dx.doi.org/10.15517/rehmlac.v8i2.10351

Fecha de recibido: 4 de septiembre de 2015 - Fecha de aceptación: 20 de octubre de 2016

Palabras clave

Bronco; México; masonería; antimasonería; elecciones

Keywords

Bronco; Mexico; Freemasonry; Anti-Freemasonry; elections

\section{Resumen}

En las elecciones estatales de 2015 en México, Jaime Rodríguez Calderón "el Bronco" sorprendió a la opinión pública al ganar la elección para gobernador de Nuevo León. En vísperas de finalizar el periodo de campaña, surgieron videos en YouTube señalando al "Bronco" como masón, adjudicándole toda una serie de mensajes religiosos, morales, políticos y sociales. Este artículo analiza los videos en el contexto de las percepciones sobre la masonería en México. Llego a la conclusión de que, debido al significado social e históricamente construido sobre la masonería en México, ha surgido una tendencia política y electoral antimasónica, con el fin de influir la intención del voto y manipular las percepciones sociales.

\begin{abstract}
In Mexico's state elections of 2015, Jaime Rodríguez Calderón "Bronco" astounded the public by winning the election to become governor of Nuevo León. Near to the end of the campaign, some videos appeared on YouTube identifying "Bronco" as a mason, adjudicating a series of religious, moral, political and social messages. This article analyzes these videos in the context of the perceptions about masonry in Mexico. I conclude that given a social and historical construction of the meaning of masonry in Mexico, an antimasonic political and electoral trend has emerged, with the objective of influencing voter's intentions and manipulating social perceptions.
\end{abstract}

\section{Introducción}

En un país sumamente religioso -mayormente católico- como lo es México, la masonería es objeto de intrigas y desconfianza; esto se había mantenido en un plano 
eminentemente social, relacionado con lo personal, con lo religioso y con la vox populi. Sin embargo, las creencias populares sobre la masonería en México se han infiltrado en otros aspectos de la vida humana como la política. Tal fue el caso de la campaña antimasónica contra el hoy gobernador del estado mexicano de Nuevo León, Jaime Rodríguez Calderón el "Bronco", durante el periodo de elecciones en la primera mitad del 2015.

El caso del Bronco reviste un especial interés para los estudiosos de elecciones y campañas políticas. La campaña antimasónica es un claro ejemplo de la vinculación entre lo privado -creencias personales, religión-y lo público -elecciones políticas- que apunta a explotar el desconocimiento para fines propagandísticos y políticos. Así, en México la masonería en tiempos electorales puede resultar ser una útil herramienta de "campañas negativas"1.

En el presente artículo estudio la campaña antimasónica contra el ahora gobernador de Nuevo León, Jaime Rodríguez Calderón “el Bronco", a partir del análisis de videos que se difundieron por la plataforma de YouTube ${ }^{2}$. Los videos muestran una narrativa antimasónica apoyada por imágenes de símbolos masones y no masones. Parto de las preguntas de investigación: ¿cómo es la narrativa en los videos?, ¿cuáles símbolos se utilizan y por qué?, ¿por qué los videos se podrían considerar "antimasónicos”? En esta línea, parto de la hipótesis de que el simbolismo utilizado en los videos corresponden, más que nada, al imaginario de lo que se cree que es masonería en México. Si bien mucho de los símbolos que se utilizan en los videos sí corresponden a símbolos masones, el asunto es el significado social adquirido entre la población mexicana.

Para fines de mi estudio divido mi artículo en cinco partes. En la primera parte expongo algunas herramientas teórico-conceptuales que me brindarán el soporte metodológico para el análisis. En la segunda parte doy un breve bosquejo histórico de la situación de la masonería en México, un poco apoyando la idea de que a la par de la evolución de la masonería en este país se ha ido formando un imaginario colectivo sobre el mismo que no se relaciona mucho con lo primero. En la tercera parte esbozo un recuento de las elecciones de 2015 para contextualizar los videos. En la cuarta parte realizo el análisis empírico de los videos. En la quinta y última parte ofrezco una serie de reflexiones finales.

\footnotetext{
${ }^{1}$ David Mark, Going Dirty. The Art of Negative Campaigning, updated edition (Lanham: Rowman \& Littlefield Publishers, 2009).

${ }^{2}$ Para un estudio sobre la recurrencia a los videos de YouTube en estudios académicos, véase Kayvan Kousha, Mike Thelwall y Mahshid Abdoli, "The role of online videos in research communication: A content analysis of YouTube videos cited in academic publications 2012", Journal of the American Society for Information Science and Technology 63, no. 9 (2012): 1710-1727. Para el estudio sobre anuncios políticos en YouTube véase Travis N. Ridout, Erika Franklin Fowler y John Branstetter, "Political Advertising in the 21st Century: The Rise of the YouTube Ad" (ponencia presentada en la reunión anual de American Political Science Association), Washington D.C., 2-5 de septiembre 2010 [citado el 24 de agosto de 2016]): disponible en http://papers.ssrn.com/sol3/papers.cfm?abstract id $=1642853$
} 


\section{Video, signo, miedo y campaña negativa: herramientas teórico- conceptuales}

Si bien los videos se han utilizado desde la década de 1930 para el análisis de la sociedad -específicamente en el campo de la antropología social-, no sería hasta finales del siglo XX e inicios del siglo XXI en que esta práctica se incrementaría considerablemente ${ }^{3}$. Los videos forman parte del análisis cualitativo de un objeto de estudio, y son insumo de la investigación por el material visual que depende en sus significados para interpretación del observador, ya sea producido por actores o científicos sociales. En otras palabras, el video provee de "datos visuales",

De acuerdo con Knoblauch, Schnettler y Raab ${ }^{5}$, la manera en que los datos visuales se construyen distingue dos situaciones. La primera, y muy importante, es que los datos son manipulados por medio de varios procedimientos técnicos, ya sea la manera en que algo se graba, la manera en que se dispone el escenario para grabar, o la manera en que fueron pensadas las escenas en un video. La segura situación se relaciona en cómo un video trata un tema, ya que puede intentar ser una fiel copia de algún aspecto específico del comportamiento de la sociedad, hasta una representación hecha de manera tal que pretenda dar un mensaje específico. En esta línea, Heath y Luff ${ }^{6}$ establecen que los videos "se están convirtiendo en recursos penetrantes, usados por agentes públicos o privados, para escudriñar la conducta y saber en dónde intervenir”. En este análisis se recolectarán los datos visuales a partir de estas tres premisas.

Jewitt ${ }^{7}$ distingue cinco formas en las que un video puede usarse: videos participativos, videografía, utilización de videos existentes, videos inductivos, videos de trabajo de campo. Cada uno de estos muestra datos visuales de manera diferente, ya sea que el video sea una documentación de lo que se quiere estudiar, sea una herramienta para dar voz a los sujetos de estudio, sea para estudio del video en sí mismo en lugar de producirlo, ya sea para inducir reflexiones a partir del mismo, o para observación y descripción del sujeto de estudio. Para el objeto de estudio del presente artículo se utilizarán videos ya existentes.

\footnotetext{
${ }^{3}$ Hubert Knoblauch, Bernt Schnettler y Jürgen Raab, "Video-Analysis. Methodological Aspects of Interpretive Audiovisual Analysis in Social Research", en Video Analysis: Methodology and Methods Qualitative Audiovisual Data Analysis in Sociology, Knoblauch, Schnettler, Raab y Hans-Georg Soeffer eds., (Frankfurt: Peter Lang, 2012), 17-19.

${ }^{4}$ Knoblauch, Alejandro Baer, Eric Laurier, Sabine Petschke y Schnettler, "Visual Analysis. New Developments in the Interpretative Analysis of Video and Photography", Forum: Qualitative Social Research 9, no. 3, (2008 [citado el 8 de junio de 2016]): disponible en http://www.qualitativeresearch.net/index.php/fqs/article/view/1170/2593

${ }^{5}$ Knoblauch, Schnettler y Raab, "Video-Analysis", 12.

${ }^{6}$ Christian Heath y Paul Luff, "Video Analysis and Organisational Practice", en Video Analysis, 36.

${ }^{7}$ Carey Jewitt, An introduction to using video for research (National Centre for Research Methods Working Paper), Londres, marzo de 2012.
} 
En el video, aparte de estudiar sus implicaciones como un todo, se analizan las imágenes que en él aparecen. ¿Por qué sería importante estudiarlas? De acuerdo con Baer y Schnettler ${ }^{8}$ la vinculación de "imagen" con el "enfoque cualitativo" supone vías de aproximación a formas narrativas y visuales de lo intangible pero existente. En esta línea, un video es un constructo que se apegará siempre al enfoque interpretativo del estudioso. Así, el lenguaje emanado de los videos y las narrativas que los acompañan es un lenguaje que no pretende representar la realidad, sino que pretende comunicar un significado que tiene contexto en las relaciones sociales?.

Los datos visuales -las imágenes- son, ante todo, signos, los cuales son algo que representan o se refieren a algo en particular, y que se sitúa en lugar de su objeto. Este algo, o representamen, crea significados en los interpretantes -o receptores del mensaje-, dependiendo de la exégesis que éstos le otorguen ${ }^{10}$. Los representamenes se producen en lo que Lotman ${ }^{11}$ llama semiósfera, aquél espacio delimitado por los propios significados que emanan del mismo, y que se producen por medio del lenguaje, signos y percepciones.

Ahora bien, los videos objetos de mi estudio son parte de lo que he caracterizado como una "campaña negativa". Si bien la "negatividad" en una campaña depende de la perspectiva a través de la cual se mire, las campañas negativas implican acciones para ganar una elección por medio de ataques a los oponentes ${ }^{12}$. En este sentido, lo que se observa en los videos, más que ganar la elección, se trató de que el candidato la perdiera por medio de los ataques a través de videos acerca de su rasgo como masón. Lo anterior apunta al fomento de un miedo político, el cual es la combinación de la racionalidad con la pasión necesaria para el impulso de acciones colectivas de los sujetos individuales, de la sociedad civil y las élites con el fin de conseguir vitalidad política ${ }^{13}$.

En suma, los videos proporcionan datos visuales que tienen un alcance muy profundo en la audiencia a la que se pretende llegar, además de que han sido manipulados e intentan brindar un mensaje específico que apunta a promover un miedo político con base en una campaña negativa. Los datos visuales son, por un lado, un constructo social en el que interactúan tanto los emisores cuanto los receptores del mensaje, y, por otro lado, son signos que proporcionan de significados diferentes dependiendo la percepción del

\footnotetext{
${ }^{8}$ Baer y Schnettler, "Hacia una metodología cualitativa audiovisual. El vídeo como instrumento de investigación social", en Investigación cualitativa en Ciencias Sociales. Temas problemas y aplicaciones, ed. Aldo Merlino (Buenos Aires: Cengage Learning, 2009).

${ }^{9}$ Ian Burkitt, "Relations, Communication and Power", en The Politics of Constructionism, eds. Irving Velody y Robin Williams (Londres, California y Nueva Delhi: Sage Publications, 1998), 123-124. En este mismo volumen, Velody y Williams establecen que el "Construccionismo" como concepto que no es una "teoría del conocimiento, sino un diálogo antifundacional". Es decir, parte del diálogo y la interacción, y no de la esencia de las cosas. Véase Irving Velody y Robin Williams, "Introduction", en The Politics of Constructionism, eds. Irving Velody y Robin Williams (Londres, California y Nueva Delhi: Sage Publications, 1998), 2.

${ }^{10}$ Charles S. Pierce, La ciencia de la Semiótica (Buenos Aires: Editorial Nueva Visión, 1978), 22.

${ }^{11}$ Iuri Lotman, La Semiósfera I. Semiótica de la cultura y del texto (Madrid: Universitat de València, 1996).

${ }^{12}$ Mark, Going Dirty, 2.

${ }^{13}$ Corey Robin, Fear. The History of a Political Idea (Oxford: Oxford University Press, 2004), 4, 31-50.
} 
interpretante. Lo anterior supone un enfoque cualitativo de análisis que debe basarse en un riguroso método interpretativo para no caer en subjetividades.

\section{La masonería en México}

El objetivo de este apartado es exponer la evolución de la masonería en México y Nuevo León, además de trazar el proceso de la percepción sobre ella. Si bien no intento realizar una descripción exhaustiva ${ }^{14}$, sí pretendo contextualizar a mi objeto de estudio. Para este apartado me interesa enfatizar que la masonería ha tenido un papel político relativamente importante en la historia de México, pero que se ha atenuado con el paso de los años. No así, empero, las percepciones antimasónicas, las cuales han estado siempre presentes.

Según Vázquez ${ }^{15}$, hay noticias de la existencia de masones en el territorio nacional mexicano desde 1810. Aunque existen relatos de la participación de masones en el proceso de independencia nacional, no hay constancias históricas de que esto haya sucedido. Hay debate sobre la participación política temprana de las sociedades masonas, ya que a la par de la consolidación de los primeros dos grandes grupos masónicos en México, entre 1822 y 1830, surgieron sociedades secretas, paramasónicas, patrióticas, y centros de acción política, ${ }^{16}$ los cuales estuvieron inmiscuidos en mayor medida en los procesos políticos del México independiente. De hecho, de acuerdo con la autora citada ${ }^{17}$, la idea de que la masonería fue un elemento ideológico y organizacional para la independencia deriva, principalmente, de la literatura antimasónica.

No sería hasta la consolidación del Rito Nacional Mexicano, en 1868, cuando los grupos integrantes -identificados como masónico-patrióticos- darían uso político a ésta estructura masónica, contraviniendo los fines apolíticos de la tradición especulativa londinense $\mathrm{e}^{18}$. A partir de este entonces habría una tradición de liberalismo político en los grupos masónicos dedicados a la política, lo que implicó el aumento de rencillas con la Iglesia católica. Esto se relaciona con una situación internacional que mantuvo dos tendencias; por un lado, la masonería en los países anglosajones y nórdicos se integró con

\footnotetext{
${ }^{14}$ Para una visión integral y sucinta del estudio de la historia de la Masonería en México, véase María Eugenia Vázquez Semadeni, "Historiografía sobre la masonería en México. Breve revisión”, REHMLAC 2, no. 1 (mayo-noviembre 2010 [citado el 15 de abril de 2016]): disponible en http://revistas.ucr.ac.cr/index.php/rehmlac/article/view/6608/6297

${ }^{15}$ Vázquez Semadeni, "La masonería en México, entre las sociedades secretas y patrióticas, 1913-1830”, REHMLAC 2, no. 2 (diciembre 2010-abril 2011 [citado el 23 de mayo de 2016]): disponible en http://revistas.ucr.ac.cr/index.php/rehmlac/article/view/6594/6285

${ }^{16}$ Vázquez Semadeni, "La masonería en México", 21-23.

${ }^{17}$ Vázquez Semadeni, "La masonería en México", 23.

${ }^{18}$ Carlos Francisco Martínez Moreno, "Estado Nación laico y secularización masónica en México", REHMLAC 3, no. 2 (diciembre 2011-abril 2012 [citado el 6 de julio de 2016]): disponible en http://revistas.ucr.ac.cr/index.php/rehmlac/article/view/6575/6266
} 
los ritos religiosos - principalmente protestantes- y la actividad política, y, por otro lado, los ideales de la masonería en países católicos se relacionaron con el liberalismo, el cual pugnaba la separación de Iglesia y Estado, aunado a la exaltación del individuo frente a estas instituciones ${ }^{19}$. En lugar de aglutinar, la vinculación de masonería y política implicó la escisión total de la Iglesia. Si bien el catolicismo ya había condenado a la masonería por su secrecía y el juramento de sus miembros desde el siglo XVIII ${ }^{20}$, esta afrenta no había adquirido matices políticos como en el siglo XIX.

Volviendo a México, lo anterior fue diluido con la aparición de la logia de Cristo en 1870, con Porfirio Díaz al frente, y la cual ayudaría al general oaxaqueño a llegar a la presidencia de México. Una vez en el poder político, Díaz optó por una "política de conciliación" entre Iglesia y Estado, lo que significó vigencia de las Leyes de Reforma, pero permisibilidad a las actividades religiosas masivas. Aunado a esto, Díaz se esforzó en controlar tanto a los grupos masónicos cuanto a los grupos religiosos y político-liberales, sin dar cierta preferencia a alguno de ellos; es en este contexto de "cierta libertad" cuando surgieron las obras Satán y Cía. y La Masonería pintada por sí misma, inter alia, libros eminentemente antimasónicos ${ }^{21}$.

A la caída de Díaz, y después del turbulento periodo de la Revolución Mexicana, el liberalismo político pareció haber triunfado. En opinión de García ${ }^{22}$, la "Constitución de 1917 fue la edición corregida y aumentada de la Constitución de 1857 (ante la cual los masones patrióticos hacían su juramento, en lugar de la práctica tradicional con la Biblia), [...] fue obra de la masonería". No obstante, esto no necesariamente significa que la masonería mexicana se consolidó en el poder político. De acuerdo con Trueba ${ }^{23}$, los ideales masónicos sobre el liberalismo "a ultranza" ya no se relacionaron tanto con el proyecto de Estado-nación que surgió después de la Revolución, el cual se caracterizó por el fortalecimiento de un Estado, caso contrario al liberalismo que pugnó por un Estado mínimo. Así, de 1940 hasta inicios del siglo XXI, la masonería fue perdiendo, poco a poco, su influencia política ${ }^{24}$.

Sin embargo, el fomento de percepciones antimasónicas nunca cesó. Como recuerdan Vázquez ${ }^{25}$ y Trueba $^{26}$, de 1884 a 2010 hubo mucha mayor difusión literaria

\footnotetext{
${ }^{19}$ José Antonio Ferrer Benimeli, La masonería como problema político religioso (Tlaxcala: Fideicomiso Colegio de Historia de Tlaxcala, Comisión Estatal de las Conmemoraciones, Universidad Autónoma de Tlaxcala, Embajada de España, Consulado de España en Tlaxcala, Gobierno del Estado de Tlaxcala, 2010), $68,72$.

${ }^{20}$ Ferrer Benimeli, La masonería, 71.

${ }^{21}$ José Luis Trueba Lara, Masones en México. Historia del poder oculto (México D.F.: Grijalbo, 2007), 202209.

${ }^{22}$ Jesús García Gutiérrez (Félix Navarrete), La masonería en la historia y en las leyes de Méjico (México D.F.: Ed. Jus, 1957), 149.

${ }^{23}$ Trueba Lara, Masones en México, 260-262.

${ }^{24}$ Trueba Lara, Masones en México, 276.

${ }^{25}$ Vázquez Semadeni, "Historiografía", 16-29.
} 
antimasónica que masónica, además de la circulación de ideas antimasónicas en periódicos católicos y conservadores como Voz de México, Pájaro Verde, Defensor Católico, El Tiempo, Peoresnada, El Hombre Libre ${ }^{27}$. En esto no tomo en cuenta los estudios históricos con rigor científico, sino obras de divulgación.

Para el caso del norte de México, y específicamente de Nuevo León, de 1868 a 1936 las logias masónicas pasaron de desempeñar un papel discreto y fundamentalmente ritualista, a actividades de instrucción, filantropía, y acción política ${ }^{28}$. Las actividades masónicas en Nuevo León iniciaron en 1845, y tuvieron relativa autonomía de acción incluso cuando, se pensaba, hubo un intento de centralizar las actividades masónicas nacionales con base en la Gran Dieta Simbólica ${ }^{29}$. Esto no sucedió, y en 1905 se fundó, por el Gral. Bernardo Reyes, la Gran Logia del Estado de Nuevo León con sede en el municipio de Dr. González ${ }^{30}$.

Lo anterior refleja una afinidad de la masonería mexicana al pensamiento liberal mexicano hasta la actualidad, implícito en las Leyes de Reforma que contravinieron la influencia de la Iglesia católica en México. Esto, a su vez, ocasionó que los viejos “dimes y diretes" ${ }^{\prime 31}$ entre la Iglesia y los masones aumentaran, causando una serie de sentimientos antimasónicos y mitos sobre actividades masónicas. Al presente, aún se pueden observar las tendencias liberales de los masones mexicanos; por ejemplo, en la Carta Nayarit documento que emitió la Confederación de Grandes Logias Regulares de los Estados Unidos Mexicanos en 2015- se lee, inter alia, "Que entre el gobierno y el episcopado mexicano, sea siempre la norma perfecta, la delimitadora del estado laico, no permitiremos retrocesos donde lo que debe prevalecer es la separación en forma determinante entre el Estado y la iglesia",32.

De esta breve reseña histórica se pueden obtener dos conclusiones. La primera es que la masonería tuvo un papel político relativamente importante a finales del siglo XIX e inicios del siglo XX. A partir del intento de institucionalizar la Revolución Mexicana, la

\footnotetext{
${ }^{26}$ Trueba Lara, Masones en México, 202-209.

${ }^{27}$ Vázquez Semadeni, “'He aquí los planes de la falsa filosofía contra la religión y el Estado'. La teoría de la conspiración masónica en Nueva España/México, 1738-1940" (ponencia presentada en el IV Simposio Internacional de Historia de la Masonería y los Movimientos Asociativos Latinoamericanos y Caribeños: Prácticas asociativas y Modernidad, siglos XVIII - XXI, Universidad de Costa Rica, San José, 2015).

${ }^{28}$ Marco Antonio Flores Zavala, "La masonería en el centro-norte de México, 1869-1914", REHMLAC 6, no. 1 (mayo-diciembre 2014 [citado el 12 de abril de 2016]): disponible en http://revistas.ucr.ac.cr/index.php/rehmlac/article/view/15229/14528

${ }^{29}$ Rogelio Aragón, "Porfirio Díaz y la 'Gran Dieta Simbólica': ¿la masonería mexicana bajo control?", REHMLAC 7, no. 2 (diciembre 2015-abril 2016 [citado el 12 de abril de 2016]): disponible en http://revistas.ucr.ac.cr/index.php/rehmlac/article/view/22695/23154

${ }^{30}$ Jesús Ramiro González Contreras, "El origen de la masonería en Nuevo León” (ponencia presentada en el Quinto Congreso de Historia Municipal del Noreste, 6 de octubre de 2012).

${ }^{31} \mathrm{O}$, como recuerda Vázquez Semadeni, “'He aquí los planes", aumentó el alcance de la "teoría de la conspiración masónica".

${ }^{32}$ Revista Delta, "Manifesto del documento "Carta Nayarit"”, 19 de junio de 2016, citado el 30 de agosto de 2016, http://revistadelta.org.mx/2016/07/19/manifesto-del-documento-carta-nayarit/
} 
masonería como organización fue perdiendo su influencia política -aunque esto no significa que no haya masones influyentes en la política. Sin embargo, y como segunda conclusión, las percepciones antimasónicas continuaron y, sobre todo, se quedaron en el imaginario mexicano, como se verá en el apartado de los análisis de los videos. Esto se puede relacionar con la continuación de la ideología liberal entre masones mexicanos, tal como muestra la Carta Nayarit, o incluso en otros pronunciamientos contra las modificaciones constitucionales en materia religiosa ${ }^{33}$.

\section{Las elecciones de 2015 en Nuevo León}

Ahora describiré la coyuntura electoral en el estado de Nuevo León con el fin, también, de contextualizar el objeto de estudio. El 7 de junio de 2015 se llevaron a cabo elecciones para gobernador en el estado mexicano de Nuevo León; compitieron diez candidatos a gobernador, de entre los cuales fue electo Jaime Rodríguez Calderón alias "el Bronco". La elección del Bronco resulta histórica puesto que rompió con el bipartidismo tradicional en Nuevo León, aunado a que ha sido el primer candidato independiente en ser gobernador de la entidad en medio de engaños estadísticos e informativos ${ }^{34}$.

Además de lo anterior, el candidato independiente tuvo desventajas frente a los candidatos de partidos políticos en materia de financiamiento y acceso a medios de comunicación. De acuerdo con Berumen y Medellín ${ }^{35}$, El Bronco tuvo que acudir a una estrategia de marketing político desde el inicio, para juntar las firmas requeridas en el plazo exigido por la reforma electoral (103, 249 votos en 49 días), y en razón de que los medios de comunicación mostraron un favoritismo inicial a la candidata del Partido Revolucionario Institucional (PRI).

La candidatura independiente del Bronco también debe entenderse en un ámbito de fuerte promoción democrática y participación ciudadana, aunque también con una desafección y desinterés político de los electores ${ }^{36}$. En esta línea, el Bronco acudió a una

\footnotetext{
${ }^{33}$ Fernando Lozano Galindo, "Reforma del 24 Constitucional es retroceso histórico, aseguran masones", Hidrocálido (24 de abril de 2012 [citado el 31 de agosto de 2016]): disponible en http://hidrocalidodigital.com/local/articulo.php?idnota $=8745$

${ }^{34}$ Abraham Nuncio, "Nuevo León: entre la insularidad y el bipartidismo", El Cotidiano 193 (2015): 23-36.

${ }^{35}$ Gladys Y. Berumen Villarruel y Laura N. Medellín Mendoza, "Marketing de los candidatos a la gubernatura de Nuevo León en las redes sociales durante el proceso electoral de 2015", Apuntes electorales, XV, no. 54 (2015): 66-67.

${ }^{36}$ Claire Wright y Francisco Sánchez García, "Candidaturas independientes y desafección política: Actitudes ciudadanas en Nuevo León", en Panorama de la reforma electoral 2014 en México. Debates y análisis con experiencias desde el estado de Nuevo León, coords. Gerardo Támez González y Xóchitl Arango Morales (Ciudad de México: Editorial Tirant Lo Blanch, 2016), 89-107; Juan de Dios Martínez Villarreal y Claire Wright, "Participación política y actitudes ciudadanas en Nuevo León: Un análisis del escenario pre-electoral 2015", en Panorama de la reforma electoral 2014 en México. Debates y análisis con experiencias desde el estado de Nuevo León, coords. Gerardo Támez González y Xóchitl Arango Morales (Ciudad de México: Editorial Tirant Lo Blanch, 2016), 69-87.
} 
intensa campaña en redes sociales para la promoción de su imagen política, alcanzando más de cinco millones de interacciones en las plataformas de YouTube, Twitter y Facebook ${ }^{37}$. Todo lo antedicho hizo posible que el candidato independiente revirtiera las estadísticas en su contra, ganando las elecciones con un $48.82 \%$ de los votos a su favor.

De febrero a junio de 2015 -tiempo en que incurrieron las campañas políticas- hubo una tendencia a la baja en las preferencias electorales por los partidos políticos tradicionales. En febrero, las encuestas otorgaban un $39 \%$ de la intención del voto al PRI, un $28 \%$ al Partido de Acción Nacional (PAN), y un $33 \%$ para el resto de los candidatos ${ }^{38}$. En mayo, y debido al favoritismo al que ya he aludido, las encuestas otorgaron, en promedio, un $35 \%$ de las preferencias al PRI, y un $35 \%$ al PAN. En las encuestadoras de los medios impresos ya figuraba el Bronco con un promedio de $38 \%$ de la intención del voto - de hecho éstos se acercaron más al resultado final de la elección. Para junio el candidato independiente se posicionó en el primero lugar con respecto a la intención del voto; $42 \%$ frente a $29 \%$ del PRI y $24 \%$ del PAN ${ }^{39}$.

En el periodo de tiempo ya referido aparecieron los videos que, en conjunto, formaron una "campaña negativa" con base en sentimientos antimasones. Por un lado, esto se pudo deber al cambio en las tendencias de la intención del voto. Por otro lado, no obstante, esto también se pudo deber a que el Bronco se alejó de grupos religiosos con los cuales había hecho un acercamiento previo. La evangelista Elvira Orta así lo expresó en una nota periodística en el periódico Milenio el 30 de mayo de 2015, cuando consideró una "traición" el hecho de que a pesar de haberlo llevado a 44 municipios de Nuevo León para promover su mensaje político, el Bronco fundó su asociación civil -con la que participó en las elecciones- "Cerebro, Corazón y Carácter", encabezada por dos de los principales masones de la ciudad de Monterrey ${ }^{40}$. De igual manera, en el portal de notas de difusión "Regiando", en un escrito del 29 de mayo de 2015 intitulado "Jaime Rodríguez: Entre la masonería, el poder y la política" se lee "a pesar de haber entregado su vida a Cristo y ser bautizado en agua, Jaime Rodríguez actualmente rehúye de sus obligaciones con esta religión..." ${ }^{41}$. En este tenor, a mediados de mayo empezaron a aparecer una serie de videos en las redes sociales "acusando" al Bronco de masón, que llegó a tener para finales del mes casi 30 mil visitas ${ }^{42}$. Cabe destacar que aun cuando en uno de los videos -que analizaré

\footnotetext{
${ }^{37}$ Berumen y Medellín, "Marketing de los candidatos", 81.

${ }^{38}$ Berumen y Medellín, "Marketing de los candidatos", 67.

${ }^{39}$ Nuncio, "Nuevo León", 26-27.

${ }^{40}$ Francisco Zuñiga, "Decepcionó a nuestras iglesias, asegura evangélica", Milenio, 30 de mayo de 2015 , citado el 2 de septiembre de 2016, http://www.milenio.com/politica/Decepciono-iglesias-aseguraevangelica 0 527347311.html

${ }^{41}$ Regiando, “Jaime Rodríguez: Entre la masonería, el poder y la política”, Regiando, 29 de mayo de 2015 , citado el 2 de septiembre de 2016, http:/www.regiando.com/jaime-rodriguez-entre-la-masoneria-el-poder-yla-politica/

42 José Gil Olmos, "Las diabluras de 'El Bronco"”, Proceso, 27 de mayo de 2015, citado el 2 de septiembre de 2016, http://www.proceso.com.mx/405544/las-diabluras-de-el-bronco
} 
posteriormente- el actual procurador de justicia de Nuevo León, Roberto Flores Treviño, afirma que el Bronco es masón, alrededor de las fechas en que la campaña negativa se suscitó el mismo candidato independiente negó serlo ${ }^{43}$.

Las elecciones para gobernador de Nuevo León estuvieron marcadas por el uso extensivo de redes sociales, lo cual repercutió, en gran medida, para la victoria electoral del Bronco. La oposición política, al inicio, se apegó a métodos más tradicionales de difusión y propaganda política, toda vez que hubo mucho mayor gasto en spots de radio, televisión y propaganda electoral en sitios públicos por parte del PRI y del PAN, que por parte del candidato independiente; esto se confirma por el hecho de que el Bronco recibió menos del uno por ciento del tope de gastos de campaña de los partidos políticos, por lo que acudió a la iniciativa privada para reunir casi 9 millones de pesos vis-à-vis 42.3 millones del PRI y 39.4 millones del PAN ${ }^{44}$. Por ello, entre mayo y junio -la recta final de las campañas- la oposición hizo uso extensivo de redes sociales, no solo para sus fines electorales, sino también para promover una campaña negativa en contra de la candidatura del Bronco. Sin embargo, probablemente, la reacción fue tardía.

Además, como demuestra un estudio de Parametría ${ }^{45}$, un $65 \%$ de la población que votó por el Bronco tenía entre 18 y 25 años, mientras que el grueso de la población religiosa ${ }^{46}$ se ubica en las personas de entre 30 y 70 años $^{47}$. En Nuevo León el porcentaje de población católica entre 19 y 24 años es de $8.7 \%$, y de 29 a $60+$ años es de $46.9 \%$, mientras que el $26.6 \%$ de la población tiene entre 15 y 29 años frente a $43.3 \%$ de entre 30 y 75+ años. Cabe destacar que de una población de 4 millones 200 mil personas, 3 millones 800 mil son católicos (casi el $88 \%$ de la población), pero el voto se dividió en la población mayor a los 25 años entre el resto de los candidatos. En otras palabras, los más jóvenes y menos religiosos que votaron por el Bronco formaron un conjunto sólido frente al resto de la población, aunado a que, se podría decir, fueron los menos susceptibles a ser influidos por la campaña negativa con base en sentimientos antimasónicos.

Lo anterior no reduce la importancia del hecho de que aún continúan ciertas percepciones antimasónicas en México. Por ello, en la siguiente sección me concentraré en analizar los videos de propaganda antimasónica que se dirigen contra el Bronco. Como ya inferí, los videos surgen en un contexto de tendencias que desfavorecen a la oposición política, y en el marco de una población mayoritariamente católica.

\footnotetext{
${ }^{43}$ Osvaldo Robles, "Invita Jaime a Felipe, pero sin el PAN", El Norte, 28 de mayo de 2015, citado el 2 de septiembre de 2016, http://www.elnorte.com/aplicaciones/articulo/default.aspx?id=551506

${ }^{44}$ Berumen y Medellín, "Marketing de los candidatos", 69.

${ }^{45}$ Carta Paramétrica, “¿Quiénes votaron por 'El Bronco'?”, Parametría. Encuesta Estatal realizada a votantes a salida de urna, 2015, http://www.parametria.com.mx/carta parametrica.php?cp=4774

${ }^{46}$ Aquí considero, básicamente, catolicismo, protestantismo, pentecostal, evangélica y cristiana. Carta Paramétrica, "¿Quiénes...?”.

${ }^{47}$ Gobierno de Nuevo León, Estadísticas de población en Nuevo León, 7 de noviembre de 2014, citado el 5 de septiembre de 2016, http://archivo.nl.gob.mx/?P=nl poblacion
} 


\section{Los videos antimasónicos en las elecciones de 2015}

En este apartado analizaré tres videos antimasónicos contra el candidato neoleonés, publicados en la plataforma YouTube a finales de mayo e inicios de junio de 2015. Como ya fueron removidos de la plataforma en línea -perdiéndose así los títulos originales-, los enumero para facilidad metodológica ${ }^{48}$. Para esta parte me apoyo principalmente en las obras de Mark ${ }^{49}$, Tucker $^{50}$, Rosen ${ }^{51}$ y Lewis ${ }^{52}$, entre otras más. Mi argumento es que en los videos se integran elementos antimasónicos o no masónicos con el objetivo de promover una campaña negativa en contra del Bronco.

El Video 1 dura 01:12 minutos y lo divido en cuatro partes. La primera parte abarca del minuto 00:00 a 00:16; en ésta se observa un círculo de personas vestidas de negro primero con la frente al suelo y luego arrodilladas, y una persona vestida de rojo al centro del círculo que porta un bastón y un turíbulo. En esta parte se insertan dos textos; el primero es una cita de la Biblia (2 Juan 1:17) que habla del anticristo, y el segundo dice "el Bronco nos engaña". En la segunda parte, que abarca los minutos 00:16 a 00:36, se muestra una imagen con pie de foto que muestra una reunión de El Bronco con masones. Aquí también hay dos textos que en conjunto se leen "Bronco se bautizó evangélico, pero en realidad es masón". Al inicio de la tercera parte, del minuto 00:36 a 00:44, se observa un anillo con un símbolo masón, para inmediatamente dar paso a una imagen de José Mireles Valverde y a un texto que dice "por eso apoya a Mireles",53, y después mostrando cuatro personas ataviadas con prendas masónicas, entre ellos el actual procurador de justicia Roberto Flores Treviño. En la cuarta y última parte vuelve a aparecer la escena de la primera parte más un texto inicial que dice "los masones rechazan a Jesús" y otra cita de la Biblia (2 Corintios 11:14); acto seguido las personas vestidas de negro dejan caer sus prendas, descubriendo mujeres desnudas, al tiempo en que aparece otro texto que menciona "el caballo es un símbolo masón", para finalizar el video con el logo de campaña del Bronco.

\footnotetext{
${ }^{48}$ Los videos se encuentran adjuntos a este artículo en la plataforma de la REHMLAC+.

${ }^{49}$ Mark, Going Dirty.

${ }^{50}$ Prentiss Tucker, The Lost Key. An Explanation of Masonic Symbols (Seattle: Harry M. Welliver, 2005 [1927]).

${ }_{51}^{5}$ Pablo Rosen, Satan y Cia. (México: Imp. Guadalupana de R. Velasco, 1888).

52 James R. Lewis, Witchcraft Today. An Encylopedia of Wiccan and Neopagan Traditions (Santa Barbara: ABC-CLIO Inc., 1999).

${ }^{53}$ José Manuel Mireles Valverde -cirujano egresado de la Universidad Michoacana- fue dirigente del grupo local de autodefensa ciudadana de Tepalcatepec, municipio del estado mexicano de Michoacán, hasta el 27 de junio de 2014. También fue uno de los coordinadores del Consejo Ciudadano de Autodefensas y Comunitarios de Michoacán, y se convirtió en un personaje de referencia dentro del surgimiento de los grupos denominados "Autodefensas", los cuales aparecieron en respuesta al crimen organizado y a la inacción del gobierno mexicano de controlar al narcotráfico en la zona. José Gil Olmos, "Mireles, el alzado líder de las autodefensas en Michoacán”, Proceso, 23 de noviembre de 2013, citado el 26 de septiembre de 2016, http://www.proceso.com.mx/358772
} 
La ceremonia de la primera y última parte del video sugiere un ritual de brujería llamado skyclad ${ }^{54}$, en el cual se realiza una práctica con base en un círculo y mujeres desnudas, además de utilizar herramientas como el turíbulo ${ }^{55}$. En el neopaganismo y la brujería, el círculo adquiere una importancia ritualista, sagrada y ceremonial ${ }^{56}$; de acuerdo con Lewis ${ }^{57}$, el uso de círculos rituales no se basó en la teología pagana tradicional, sino más bien provienen de procedimientos cabalísticos encontrados en la obra Greater Key of Solomon, la cual brinda instrucciones para "conversar" con los espíritus vía "experimentos" con base en rituales que se realizan en un círculo ${ }^{58}$. Es importante mencionar que Greater Key of Solomon fue inspirada en las figuras bíblicas del rey Salomón y su hijo Roboam.

La primera parte del Video 1 es una introducción para la segunda y tercera parte, en la que se muestra la relación del Bronco con la masonería; se intenta formar un argumento deductivo: premisa A "el Bronco es un engañador" (con base, también, en la cita bíblica); premisa B “el Bronco se bautizó evangélico pero es masón”; conclusión "el Bronco nos engaña porque es masón". En la tercera parte se introduce el signo 59 "Mireles" para apoyar la conclusión deductiva del argumento con una premisa $\mathrm{C}$ "el Bronco es masón porque apoya a Mireles", por lo que la conclusión quedaría "el Bronco nos engaña porque es masón, lo cual se demuestra en su apoyo a Mireles".

Al inicio de la tercera parte se muestra un anillo con claros símbolos masónicos: la escuadra, el compás, y al centro la G de G.A.D.U. (Gran Arquitecto del Universo) ${ }^{60}$. Al costado se puede ver lo que parece un ojo rodeado de líneas del centro hacia afuera, lo cual sugiere al sol matizado como símbolo masónico ${ }^{61}$. Todo lo anterior forma el signo "símbolo masón", que es la antesala a la tercera parte del video donde se muestra un hombre -Mireles- apuntando al lado izquierdo de su pecho en el que se reproduce el mismo símbolo, el cual está rodeado de un círculo rojo, aunado a la imagen enfocada en Roberto Flores Treviño, en cuya manga reaparece el símbolo masón. Aparentemente esta relación pretende demostrar que Mireles es masón al utilizar el símbolo masón, así como reforzar la idea de que los masones utilizan este símbolo.

Por último, en la cuarta parte del video se enfatizan dos ideas, el rechazo de Jesús por parte de los masones, y el caballo como un símbolo masón. Sin embargo, ambas premisas no brindan un argumento deductivo, lo cual se puede deber a la falta de relación entre ellas y la falta de conclusión. La primera premisa se relaciona claramente con la obra

\footnotetext{
${ }^{54}$ Lewis, Witchcraft Today, 271.

${ }^{55}$ Lewis, Witchcraft Today, 49.

${ }^{56}$ Lewis, Witchcraft Today, 58-59.

${ }^{57}$ Lewis, Witchcraft Today, xxviii.

${ }^{58}$ Greater Key of Solomon, traducido de manuscritos antiguos en el Museo Británico de Londres por Liddell MacGregor Mathers (Cincinnati: Emperor Norton Books, 1999), 15, 17-18.

${ }^{59}$ Pierce, La ciencia de la Semiótica.

${ }^{60}$ Tucker, The Lost Key, 43-49.

${ }^{61}$ Tucker, The Lost Key, 49. Ferrer Benimeli, La masonería, 161.
} 
de Taxil $^{62}$ y otras literaturas antimasónicas similares que defienden la idea de que la masonería es equivalente a una asociación anticatólica ${ }^{63}$. Aquí asumo que el signo "Jesús" se vincula con la religión católica, aunque también puede ser transitivo a otras religiones de tradición monoteísta abrahámicas. No existe en la literatura revisada alguna referencia de que el caballo sea un símbolo masón, y lo más cercano es que la herradura de caballo tiene una función de amuleto para los neopaganos y la brujería, esto derivado de culturas árabes y europeas ${ }^{64}$.

El Video 1 combina toda una serie de signos relacionados previamente con la masonería, a partir de obras antimasónicas, para reforzar una idea negativa acerca de los masones. El skyclad, por ejemplo, es en realidad una ceremonia neopagana, y no existen indicios de que la masonería realice ese tipo de ceremonias. También se utilizan signos previamente relacionados al desorden social, como la figura de Mireles. Por último, el Video 1 exalta signos relacionados con las creencias católicas, como las citas bíblicas o la figura de Jesús; esto apela a influir en una población mayoritariamente católica.

El Video 2 dura 01:59 minutos que divido en cuatro grandes secciones, las cuales, a su vez, se podrían dividir en varias subsecciones. La primera sección abarca del minuto 00:00 al minuto 00:34, y es muy rica en símbolos, textos, signos y significados; comienza con el Bronco diciendo "liberen a Mireles, no sean cabrones" [sic], para dar paso a juntar su imagen con la de otras dos personas (Mireles y Roberto Flores Treviño) enfrente del símbolo masón previamente descrito (el conjunto del compás, la escuadra, la "G" y el sol). Acto seguido empieza una narración del siguiente texto:

El masonismo [sic], o los masones, son un grupo secreto muy poderoso y extenso, de larga duración, y generalmente mal intencionado. Expertos explican que esta secta reconoce que el dios de la masonería es Lucifer. Además, menciona la necesidad de tener tres guerras, y por derecho divino se creen los dueños del planeta; jesuitas, Opus Dei, las Trece familias, etc. Sucesos en la historia han sido controlados por estos manipuladores que organizan los acontecimientos desde detrás de escena, y con motivos nefastos, o por lo menos egoístas ${ }^{65}$.

A la par que avanza la narrativa surgen numerosas imágenes, a continuación en orden de aparición: una reunión de masones, una caricatura de dos personas en blanco y negro, una imagen donde aparece el cuerpo de una persona con la cabeza de un cabrío con una estrella en la frente -comúnmente asociada con el diablo- y de fondo numerosos masones en blanco y negro, un ataúd con una persona vestida en blanco y negro al lado,

\footnotetext{
${ }^{62}$ Lèo Taxil, Les mystères de la Franc-maçonnerie (Paris: Letouzey \& Ané, 1886).

${ }^{63}$ Como, por ejemplo, en Satán y Cía., de Rosen, explícitamente se afirma que uno de los fines de la masonería es destruir al catolicismo (1888, XLIX).

${ }^{64}$ Lewis, Witchcraft Today, 148.

${ }^{65}$ Las cursivas son mías.
} 
una imagen de masones en blanco y negro, una imagen de unas personas levantando unos instrumentos largos y delgados que parecen ser palos, espadas o bastones, otra imagen con cuatro masones y un libro al frente de ellos, la imagen de Baphomet, la imagen de un rostro que se podría asociar con Lucifer, imágenes de un buque de guerra disparando, imágenes de los atentados a las Torres Gemelas, imágenes de personas de un país aparentemente africano o del Medio Oriente, una imagen de una pintura de jesuitas evangelizando y encima el símbolo de los jesuitas, la imagen de un hombre frente a una multitud y encima el símbolo del Opus Dei, la imagen de los reyes de Inglaterra y encima un esquema piramidal que expone, supuestamente, la organización de la élite mundial o las treces familias que dominan al mundo, un video corto de la caída del muro de Berlín, un soldado estadunidense en Irak o Afganistán, y otra serie de videos relacionados con esto último.

Esta primera parte del Video 2 pretende cumplir con la definición de "propaganda" de Lasswell ${ }^{66}$, a saber "el manejo de actitudes colectivas por medio de la manipulación de símbolos significativos". En este sentido, argumento que a cada signo de la primera parte de este video corresponden dos significados, el que originalmente tiene, y el que ha sido histórica y socialmente construido. El video se apoya de los significados histórica y socialmente construidos - contribuyendo a su manipulación- para manejar una actitud colectiva de rechazo a la masonería. Las imágenes recurrentes del macho cabrío, o Baphomet, (minutos 00:09, 00:11-00:15) son un buen ejemplo empírico de esto; centraré el análisis de la primera parte del Video 2 en este caso de estudio.

Alrededor de Baphomet se asocian tres símbolos: Baphomet, macho cabrío, y aquelarre o Sabbat. El primero -Baphomet- es un símbolo asociado con la figura bíblica de Satanás, y que supuestamente fue adorado por los caballeros templarios y del cual los neopaganos se deslindan ${ }^{67}$. El segundo -macho cabrío- es un significado posteriormente añadido a Baphomet, y es el animal macho de la cabra, el cual tuvo significados mitológicos asociados con la fertilidad en Grecia y Roma. El tercero -aquelarre o sabbat-, más que un símbolo o imagen, es una práctica de reunión ritualista en religiones neopaganas, de lo cual derivaron otras prácticas religiosas como el Sabbat judío en razón de que se relaciona con los solsticios y equinoccios de los años solares ${ }^{68}$. Los anteriores son los significados originales que luego se traslaparon y tergiversaron, dando lugar a un solo signo, Baphomet o aquelarre como sinónimo de Satanás, la figura bíblica, y que se manifiesta como macho cabrío.

Cabe destacar que, en la Biblia católica, los signos "Satanás" o "diablo" se asocian más a una serpiente que a un macho cabrío. La figura del macho cabrío, recurrente en el Antiguo Testamento y la Torá judía, es un medio de sacrificio a Dios, y no se relaciona con

\footnotetext{
${ }^{66}$ Harold, D. Lasswell, "The Theory of Political Propaganda”, The American Political Science Review 21, no. 3 (1927), 627.

${ }^{67}$ Lewis, Witchcraft Today, 28.

${ }^{68}$ Lewis, Witchcraft Today, xxiv y 249.
} 
la figura de "Satanás" o "diablo". El traslape entre signos, previamente descrito, han producido nuevos signos que perpetúan la tergiversación, como el "Sigilo de Baphomet", el cual es considerado ya un símbolo del satanismo ${ }^{69}$. En esta línea, si bien algunos rituales satánicos al igual que otros masónicos, han adoptado los mismos elementos simbólicos que a su vez se asemejan a prácticas de las órdenes de templarios-, es importante subrayar que debido al grado de blasfemia hacia la figura bíblica de Jesucristo, probablemente los masones excluyen dichos rituales satánicos ${ }^{70}$. Esto último lo considero fundamental para comprender el grado de "propaganda" en la correlación de símbolos y la narrativa en la primera parte del video. En una primera instancia, la primera parte del Video 2 combina una narrativa con una serie de imágenes reforzando el signo histórico y socialmente construido del Baphomet como el aquelarre asociado al diablo, y este signo asociado, a su vez, con los masones. Sin embargo, como he expuesto, el Baphomet (templarios) poco tiene que ver con el macho cabrío (fertilidad-mitología griega y romana) o con el aquelarre (neopaganismo), y más bien tendría que ver con la serpiente (diablo-Satanás-Biblia católica). Además, los mismos miembros de la iglesia de Satán reconocen que si bien comparten algunos elementos con los masones -sobre todo los derivados a rituales preexistentes como los templarios o los cabalísticos-, estos últimos no comparten los rituales por la blasfemia a la figura de Jesucristo, tal como establece la obra de LaVey.

Volviendo a la narrativa, ésta combina un discurso tendencioso apoyado por los signos previamente descritos; esto se puede observar en la utilización de nociones como "mal intencionado" o "motivos nefastos", ya que la utilización de este tipo de lenguaje asume posturas, ideas o acciones "buenas" o "malas" y, por ende, parcializadas o ideologizadas. Así, se establece la siguiente secuencia de ideas a) los masones son mal intencionados, b) los masones tienen de dios a Lucifer, c) los masones son mal intencionados porque tienen de dios a Lucifer. Éste es solo un ejemplo empírico de la correlación entre un discurso propagandístico y una serie de imágenes que se aprovechan de significados históricos y socialmente construidos, y no de los significados originales. El uso de los signos "jesuitas", "Opus Dei", "Trece familias", etc., también es parte de dicha correlación, ya que p. ej., los jesuitas y el Opus Dei son instituciones eclesiásticas que en algún momento tuvieron problemas con la jerarquía católica y, por tanto, se construyeron significados contrarios a los que originalmente tienen.

La segunda sección del Video 2 abarca 00:35 a 01:06; la primera subsección de esta parte se centra en la misma figura de Mireles del Video 1. Aquí aparecen varias fotografías

\footnotetext{
${ }^{69}$ Anton Szandor LaVey, The Satanic Rituals. Companion to The Satanic Bible (Nueva York: Avon Books, 1972). Cabe destacar que el culto institucionalizado a Satán, Satanás, Lucifer o el diablo surgió apenas en el siglo XX.

${ }^{70}$ LaVey, The Satanic Rituals.
} 
de Mireles con otros hombres armados en combinación con símbolos de la masonería. Durante esta subsección se narra el siguiente texto:

Mireles, estudiado [sic] en una universidad elitista, y estuvo en los Estados Unidos americanos trabajando por diez años, que tuvo cargos políticos en México, que tiene mucho dinero, es considerado un posible infiltrado masón que provoca la división de manera discreta, tan discreta que lo hacen de forma que en vez de dudar de ellos, mucha gente los ve con aceptación y los apoya ${ }^{71}$.

La argumentación en esta parte del video presupone que las personas deben dudar de los masones. De acuerdo con Mark $^{72}$, una campaña negativa pretende realzar los atributos negativos de un sujeto para fines de electorales y de desprestigio. En los videos antimasónicos se asume que los signos masón y masonería se relacionan con algo negativo por el constructo histórico y social en México desde el siglo XIX, tal como expuse en el segundo apartado de este texto. Así, se pretende sustentar, nuevamente, un argumento deductivo: premisa A "la masonería/el masón es algo malo", premisa B "hay que dudar de lo que es malo", conclusión "hay que dudar de la masonería/del masón". Recordando a Burkitt $^{73}$, debido a que el significado de algo se construye a partir de las relaciones sociales, y no debido al lenguaje asignado para representar una determinada realidad, entonces es comprensible el surgimiento y propagación de significados diferentes a los signos masón y masonería en tanto la secrecía y discreción de la naturaleza de éstos. Por ello fue posible fortalecer signos y significados al grado en que se tomó por verdadero el signo de masón/masonería como algo eminentemente negativo, malo, contrario a la Iglesia católica, dañino.

En la segunda subsección -que inicia con una imagen en amarillo y negro del símbolo masón- aparecen, rápida y subsecuentemente, numerosas imágenes que se pueden relacionar con pobreza, violencia, corrupción, muerte, narcotráfico, secuestro. A la par de las imágenes, se narra el siguiente texto:

Y hasta que los mexicanos no identifiquemos a nuestro verdadero enemigo la pobreza seguirá, la violencia, la corrupción. Cualquier cosa que no permita que el país resplandezca proviene de la masonería ${ }^{74}$.

Esta última frase, en cursivas, intenta vincular las imágenes con la masonería. Sin embargo, en el argumento se radicalizan, ya que los signos masón y masonería pasaron de ser "algo malo" al "verdadero enemigo". Si bien puede existir un vínculo entre

\footnotetext{
${ }^{71}$ Las cursivas son mías.

${ }^{72}$ Mark, Going Dirty.

${ }^{73}$ Burkitt, "Relations, Communication", 124.

${ }^{74}$ Las cursivas son mías.
} 
"malo/maldad" y "enemistad", no es un sine qua non. Para esta parte encuentro útil el estudio de $\mathrm{Eco}^{75}$, en el cual establece que un "enemigo" es importante para la construcción de la identidad, para fomentar el sistema de valores y para la distinción del "otro". Relacionado a esto, Gutiérrez ${ }^{76}$ establece que para la construcción discursiva del enemigo se recurre a una serie de valores y creencias preconstruidos, cultural o ideológicamente. Así, la construcción del masón como un enemigo contribuyó a la construcción de la identidad de la iglesia, aunado a que la construcción del Bronco como "un peligro para Nuevo León" (así lo establece la narrativa al final del Video 2) pretendió construir una identidad neoleonesa supuestamente afín a la identidad religiosa (católica eminentemente) y electoralmente contraria al candidato referido.

La tercera parte del Video 2 abarca los minutos 01:07 a 01:34 y se entra en la figura de Roberto Flores Treviño que también aparece en el Video 1, actual procurador de justicia de Nuevo León. En esta parte del video se señala que el procurador es masón, tal como éste lo reconoce en una entrevista en el portal de noticias "Punto Muerto" (ahora "HOTV Noticieros"). La narrativa continúa de la siguiente manera:

El abogado y consejero del candidato Jaime Rodríguez "el Bronco" actualmente es miembro de la Gran Logia de Nuevo León, y tiene el más alto nombramiento que se le puede otorgar a un masón. Teniendo en cuenta el grado de influencia en la masonería, y siendo abogado y consejero de Jaime Rodríguez, ¿sabes cuánto peligro corre Nuevo León con el Bronco como gobernador? La violencia de por sí ya expuesta por parte de el [sic] Bronco es inminente, y la fuente influenciadora [sic] sale a la $\mathrm{luz}^{77}$.

Esta parte del texto establece una vinculación Roberto Flores Treviño-Broncopeligro-violencia, aunado a la argumentación que la fuente de la violencia es, precisamente, el actual procurador de justicia. La construcción del enemigo continúa con base en el constructo social e histórico de la masonería. Sin embargo, y con base en las últimas dos narrativas, se han agregado más significados al signo masón/masonería. Como establecí en la segunda parte de este texto, la construcción histórica y social de la masonería la relacionó con algo malo por ser contrario a la Iglesia católica, pero en este video se le agrega la noción de "amenaza", "peligrosidad" o "enemigo". Así, se construye un argumento mucho más sólido que contribuye a la campaña negativa antimasónica contra el Bronco: el candidato no solo es masón, no solo es malo, no solo es contrario a la religión, sino también es peligroso, es un enemigo, y Flores Treviño, su allegado, también lo es por las mismas razones.

\footnotetext{
${ }^{75}$ Umberto Eco, Construir al enemigo (Lumen, 2012).

${ }^{76}$ Silvia Gutiérrez Vidrio, "La construcción de la imagen de López Obrador en los spots de sus adversarios", Cultura y representaciones sociales 1, no. 2 (2007), 35.

${ }^{77}$ Las cursivas son mías.
} 
La última parte del Video 2 abarca los minutos 01:35 a 01:59, y otorga una conclusión para promover un argumento inductivo. En los primeros segundos de esta parte se muestran imágenes mayormente relacionadas con la "guerra contra el narcotráfico", resultado de las políticas de Felipe Calderón como presidente de México (2006-2012). Después, se muestran íconos de programas de radio y televisión, con algunas personas, para dar paso a la imagen del Bronco con fondo negro y el símbolo masón atrás del candidato, e inmediatamente se coloca un signo de prohibición en rojo y la leyenda en blanco " $i J a i m e$ RDZ es un peligro para N.L.!”. ¿Por qué un argumento inductivo? Porque se intenta definir algo general (violencia) a partir de premisas particulares (Bronco, masonería). La narrativa que acompaña a esta última parte del video es la siguiente:

¿Es lo que quieres para Nuevo León? La violencia como la forma de reestructurar la sociedad neoleonesa es el objetivo de Jaime Rodríguez. El camuflaje es la conspiración que usa en contra del sistema, a sabiendas que él formó parte de este sistema durante más de 30 años. No lo permitamos.

Para esta parte destaco el argumento al final del video, "Jaime Rodríguez es un peligro para Nuevo León", como objeto de estudio, ya que se relaciona, metodológicamente, con la construcción de la imagen de Andrés Manuel López Obrador (AMLO) cuando fue candidato a las elecciones presidenciales de 2006. Como establecen algunos estudios ${ }^{78}$, la construcción de la "peligrosidad" de AMLO se maquinó en una campaña negativa con base en el miedo político. De acuerdo con Robin, el "miedo depende de las evaluaciones ideológicas generalizadas de virtud y vicio [...]"79, y, así como las costumbres, el miedo puede deshacerse y rehacerse. Por ello, al subrayar la "peligrosidad" del Bronco -tal como sucedió con AMLO-, se intentó reproducir un miedo con base en las evaluaciones sociales preconstruidas sobre la masonería, la cual se relaciona con algo negativo. Es importante destacar que la campaña negativa también se basó en la relación del Bronco con AMLO y otros personajes cercanos a éste, además de políticos y empresarios ${ }^{80}$.

El Video 3 dura 02:59 minutos ${ }^{81}$, y es la entrevista en el portal de noticias "Punto Muerto" (ahora "HOTV Noticieros") a Roberto Flores Treviño, en la que afirma que es masón. En el anexo se ubica la transcripción de la entrevista. El video muestra solo algunos segmentos en los que Flores Treviño habla sobre la masonería, de lo cual subraya el grado que ostenta en la jerarquía masónica, la naturaleza de la masonería y la relación de ésta con

\footnotetext{
${ }^{78}$ Gutiérrez Vidrio, "La construcción". Javier Treviño Rangel, "Pánico moral en las campañas electorales de 2006: la elaboración del "peligro para México", Foro Internacional XLIX no. 3 (2009 [citado el 21 de septiembre de 2016]): disponible en http://forointernacional.colmex.mx/index.php/fi/article/view/1971/1961

${ }^{79}$ Robin, Fear, 43.

${ }^{80}$ Véase Video 4.

${ }^{81}$ Uno similar a éste, que dura 04:51 minutos aún se encuentra en YouTube, Flores Treviño confirma que el Bronco es masón.
} 
la religión. Es importante subrayar el hecho de que la entrevista no se muestra completa, por lo que existe un sesgo en la información.

Probablemente este video fue publicado después de los dos que ya he analizado, ya que no contiene narrativa ni imágenes que contribuyan a reforzar una imagen negativa sobre la masonería. Más bien, se apoya, precisamente, del miedo previamente creado y reforzar alrededor de los signos masón y masonería. Por ejemplo, del minuto 00:03 a 00:15 Flores Treviño y una persona a su lado izquierdo exponen el grado jerárquico que el primero ostenta al interior de la masonería -específicamente de la Gran Logia de Nuevo León. Inmediatamente después de esto, se muestra una parte de la entrevista en la que Flores Treviño confirma que es el representante legal de Jaime Rodríguez Calderón. En pocas palabras, se produce un vínculo entre "el representante legal de Jaime Rodríguez Calderón” y "el masón Roberto Flores Treviño".

Al ver la entrevista completa se comprende el porqué de las intervenciones que en el Video 3 se muestran acomodadas. Esto supone que el video se editó para fines propagandísticos y, al haber sido publicado en tiempos de elecciones, también tuvo fines electorales y de campaña negativa.

\section{Consideraciones finales}

La masonería en México aún es presa de la desconfianza y desconocimiento sociales. Los videos antimasónicos contra la candidatura del Bronco, en 2015, demuestran que quienes hayan hecho los videos creyeron poder explotar, política y electoralmente, la desconfianza y el desconocimiento de la sociedad mexicana. Al ver que las estadísticas comenzaron a desfavorecer a los candidatos tradicionales, y recordando que la elección para gobernador fue un 7 de junio de 2015, los videos surgieron a finales de mayo del mismo año en un intento de revertir las tendencias de las intenciones del voto. Esto, sin embargo, no tuvo mayores efectos, ya que fue la población más joven y menos religiosa la que le otorgó la victoria electoral al Bronco.

Aunque la campaña negativa no tuvo el efecto deseado, aún continúa la promoción de un miedo político con base en percepciones antimasónicas. En la plataforma de YouTube, después de las elecciones y de que el Bronco haya rendido protesta como gobernador de Nuevo León, se han publicado dos videos más que continúan la propagación de ideas antimasónicas y de miedo político contra el Bronco ${ }^{82}$, con las mismas ideas de los videos analizados en este texto. No incluí el análisis de estos videos porque uno de mis objetivos

\footnotetext{
${ }^{82}$ Video 5: Youtube, “La Masonería Detrás de los Candidatos 'Independientes' - Jaime Rodríguez 'El Bronco",, YouTube, 8 de diciembre de 2015, citado el 23 de septiembre de 2016, https:/www.youtube.com/watch?v=vwtWnWxPkyw. Video 6: Youtube, "Jaime Rodríguez el Bronco es masón", Youtube, 10 de diciembre de 2015, citado el 23 de septiembre de 2016, https://www.youtube.com/watch?v=7vLLD2hkkuE
} 
fue concentrarme en los videos que apuntaron a una campaña negativa, por lo que son sujetos de futuras investigaciones.

Esta investigación ha podido dar cuenta de algunos orígenes de los sentimientos antimasónicos. En primer lugar, en México la gran mayoría de los sentimientos antimásonicos han sido promovidos por la Iglesia católica y por grupos conservadores afín a ésta. Lo anterior se explica porque la antigua lucha política entre liberales y conservadores mexicanos involucró a los masones, los cuales se alinearon con la ideología política liberal. Además, el eco de la bula papal emitida por Clemente XII, en 1738 -In Eminenti Apostolatus Specula, considerada la primera acción católica antimasónicaresurgió con fuerza en esta lucha, y continúa dando señales de vida en pleno siglo XXI.

La investigación también ha podido constatar los orígenes de algunos significados asociados con la masonería. El análisis de los videos sugiere que el desconocimiento a detalle sobre los rituales masónicos, aunado al carácter privado o cerrado de estos últimos, contribuyó a fortalecer significados que han trascendido al tiempo. Así, los signos masón y masonería pasaron de tener un significado que le otorga identidad, a un significado que comunica una idea o percepción. En México, la percepción comunicada ha construido una identidad muy diferente a la que originalmente y en esencia tiene la masonería. Debido al eco de la censura católica contra los masones, esta identidad histórica y socialmente construida se relaciona con todo aquello que la Iglesia católica considera nocivo: el diablo, la brujería, el paganismo, etcétera.

En suma, los datos visuales proporcionados por los tres videos analizados demuestran que los videos fueron editados para promover un fin específico. El objetivo de los datos visuales proporcionados fue la promoción de una campaña negativa con base en el miedo político contra la figura del Bronco. El miedo político se derivó de las percepciones histórica y socialmente construidas alrededor de los signos masón y masonería, aunado a la construcción de estos signos como un enemigo. Esto denota que las pugnas entre liberales y conservadores $-\mathrm{y}$ más específicamente entre catolicismo y masonería- aún continúa, y en periodo de elecciones, esto adquirió un matiz político y electoral.

\section{Bibliografía}

Aragón, Rogelio. 'Porfirio Díaz y la 'Gran Dieta Simbólica': ¿la masonería mexicana bajo control?” REHMLAC 7, no. 2 (diciembre 2015-abril 2016 [citado el 12 de abril de 2016]): disponible

en http://revistas.ucr.ac.cr/index.php/rehmlac/article/view/22695/23154

Baer, Alejandro y Bernt Schnettler. "Hacia una metodología cualitativa audiovisual. El vídeo como instrumento de investigación social". En Investigación cualitativa en Ciencias Sociales. Temas problemas y aplicaciones. Editado por Aldo Merlino. Buenos Aires: Cengage Learning, 2009. 
Berumen Villarruel, Gladys Y., y Laura N. Medellín Mendoza. "Marketing de los candidatos a la gubernatura de Nuevo León en las redes sociales durante el proceso electoral de 2015". Apuntes electorales, XV no. 54 (2015): 57-90.

Burkitt, Ian. "Relations, Communication and Power". En The Politics of Constructionism. Editado por Irving Velody y Robin Williams. Londres, California y Nueva Delhi: Sage Publications, 1998.

Carta Paramétrica. “QQuiénes votaron por 'El Bronco’?”. Parametría. Encuesta Estatal realizada a votantes a salida de urna. 2015. Disponible en http://www.parametria.com.mx/carta_parametrica.php?cp=4774

Eco, Umberto. Construir al enemigo. Lumen, 2012.

Ferrer Benimeli, José Antonio. La masonería como problema político religioso. Tlaxcala: Fideicomiso Colegio de Historia de Tlaxcala, Comisión Estatal de las Conmemoraciones, Universidad Autónoma de Tlaxcala, Embajada de España, Consulado de España en Tlaxcala, Gobierno del Estado de Tlaxcala, 2010.

Flores Zavala, Antonio. "La masonería en el centro-norte de México, 1869-1914". REHMLAC 6, no. 1 (mayo-diciembre 2014 [citado el 12 de abril de 2016]): disponible en http://revistas.ucr.ac.cr/index.php/rehmlac/article/view/15229/14528

García Gutiérrez, Jesús (Félix Navarrete). La masonería en la historia y en las leyes de Méjico. México D.F.: Ed. Jus, 1957.

Gil Olmos, José. "Mireles, el alzado líder de las autodefensas en Michoacán”. Proceso, 23 de noviembre de 2013. Citado el 26 de septiembre de 2016. http://www.proceso.com.mx/358772

Gobierno de Nuevo León. Estadísticas de población en Nuevo León, 7 de noviembre de 2014. Citado el 5 de septiembre de 2016. http://archivo.nl.gob.mx/?P=nl poblacion.

González Contreras, Jesús Ramiro. "El origen de la masonería en Nuevo León”. Ponencia presentada en el Quinto Congreso de Historia Municipal del Noreste, 6 de octubre de 2012.

Greater Key of Solomon. Traducido de manuscritos antiguos en el Museo Británico de Londres por Liddell MacGregor Mathers. Cincinnati: Emperor Norton Books, 1999.

Gutiérrez Vidrio, Silvia. "La construcción de la imagen de López Obrador en los spots de sus adversarios". Cultura y representaciones sociales 1, no. 2 (2007): 31-54.

Heath, Christian y Luff, Paul. "Video Analysis and Organisational Practice". Editado por Hubert Knoblauch, Bernt Schnettler, Jürgen Raab y Hans-Georg Soeffer. Frankfurt: Peter Lang, 2012.

Jewitt, Carey. An introduction to using video for research. National Centre for Research Methods Working Paper. Londres, 2012.

Knoblauch, Hubert, Alejandro Baer, Eric Laurier, Sabine Petschke y Bernt Schnettler. "Visual Analysis. New Developments in the Interpretative Analysis of Video and Photography". Forum: Qualitative Social Research 9, no. 3 (2008 [citado el 8 de 
junio de 2016]): disponible en http://www.qualitativeresearch.net/index.php/fqs/article/view/1170/2593

Knoblauch, Hubert, Bernt Schnettler y Jürgen Raab. "Video-Analysis. Methodological Aspects of Interpretive Audiovisual Analysis in Social Research". En Video Analysis: Methodology and Methods Qualitative Audiovisual Data Analysis in Sociology. Editado por Hubert Knoblauch, Bernt Schnettler, Jürgen Raab y HansGeorg Soeffer. Frankfurt: Peter Lang, 2012.

Kousha, Kayvan, Mike Thelwall y Mahshid Abdoli. "The role of online videos in research communication: A content analysis of YouTube videos cited in academic publications 2012". Journal of the American Society for Information Science and Technology 63, no. 9 (2012): 1710-1727.

Lasswell, Harold, D. "The Theory of Political Propaganda". The American Political Science Review 21, no. 3 (1927): 627-631.

LaVey, Anton Szandor. The Satanic Rituals. Companion to The Satanic Bible. Nueva York: Avon Books, 1972.

Lewis, James R. Witchcraft Today. An Encylopedia of Wiccan and Neopagan Traditions. Santa Barbara: ABC-CLIO Inc., 1999.

Lotman, Iuri. La Semiósfera I. Semiótica de la cultura y del texto. Madrid: Universitat de València, 1996.

Lozano Galindo, Fernando. "Reforma del 24 Constitucional es retroceso histórico, aseguran masones". Hidrocálido, 24 de abril de 2012. Citado el 31 de agosto de 2016. http://hidrocalidodigital.com/local/articulo.php?idnota $=8745$

Mark, David. Going Dirty. The Art of Negative Campaigning, updated edition. Lanham: Rowman \& Littlefield Publishers, 2009.

Martínez Moreno, Carlos Francisco. "Estado Nación laico y secularización masónica en México". REHMLAC 3, no. 2 (diciembre 2011-abril 2012 [citado el 6 de julio de 2016]): $\quad$ disponible

en http://revistas.ucr.ac.cr/index.php/rehmlac/article/view/6575/6266

Martínez Villarreal, Juan de Dios y Claire Wright. "Participación política y actitudes ciudadanas en Nuevo León: Un análisis del escenario pre-electoral 2015". En Panorama de la reforma electoral 2014 en México. Debates y análisis con experiencias desde el estado de Nuevo León. Coordinado por Gerardo Támez González y Xóchitl Arango Morales. Ciudad de México: Editorial Tirant Lo Blanch, 2016.

Nuncio, Abraham. "Nuevo León: entre la insularidad y el bipartidismo". El Cotidiano 193 (2015): 23-36.

Olmos, José Gil. "Las diabluras de 'El Bronco"”. Proceso, 27 de mayo de 2015. Citado el 2 de septiembre de 2016. http://www.proceso.com.mx/405544/las-diabluras-de-elbronco 
Pierce, Charles S. La ciencia de la Semiótica. Buenos Aires: Editorial Nueva Visión, 1978. Regiando. "Jaime Rodríguez: Entre la masonería, el poder y la política". Regiando, 29 de mayo de 2015. Citado el 2 de septiembre de 2016. http://www.regiando.com/jaimerodriguez-entre-la-masoneria-el-poder-y-la-politica/

Revista Delta. "Manifiesto del documento "Carta Nayarit"”. 19 de junio de 2016. Citado el 30 de agosto de 2016. http://revistadelta.org.mx/2016/07/19/manifesto-deldocumento-carta-nayarit/

Ridout, Travis N., Erika Franklin Fowler y John Branstetter. "Political Advertising in the 21st Century: The Rise of the YouTube Ad". Ponencia presentada en la reunión anual de American Political Science Association, Washington D.C., 2-5 de septiembre de 2010. Citado el 24 de agosto de 2016. http://papers.ssrn.com/sol3/papers.cfm?abstract id=1642853

Robin, Corey. Fear. The History of a Political Idea. Oxford: Oxford University Press, 2004. Robles, Osvaldo. "Invita Jaime a Felipe, pero sin el PAN". El Norte, 28 de mayo de 2015. $\begin{array}{lllll}\text { Citado el } & 2 & \text { de } & \text { septiembre } & \end{array}$ http://www.elnorte.com/aplicaciones/articulo/default.aspx? $\mathrm{id}=551506$

Rosen, Pablo. Satan y Cia. México: Imp. Guadalupana de R. Velasco, 1888.

Taxil, Léo. Les mystères de la Franc-maçonnerie. París: Letouzey \& Ané, 1886.

Treviño Rangel, Javier. "Pánico moral en las campañas electorales de 2006: la elaboración del 'peligro para México"”. Foro Internacional XLIX no. 3 (2009 [citado el 21 de septiembre de 2016]): disponible en http://forointernacional.colmex.mx/index.php/fi/article/view/1971/1961

Trueba Lara, José Luis. Masones en México. Historia del poder oculto. México D.F.: Grijalbo, 2007.

Tucker, Prentiss. The Lost Key. An Explanation of Masonic Symbols. Seattle: Harry M. Welliver, 2005 [1927].

Vázquez Semadeni, María Eugenia. "Historiografía sobre la masonería en México. Breve revisión". REHMLAC 2, no. 1 (mayo-noviembre 2010 [citado el 15 de abril de 2016]): $\quad$ disponible

en http://revistas.ucr.ac.cr/index.php/rehmlac/article/view/6608/6297

Vázquez Semadeni, María Eugenia. "La masonería en México, entre las sociedades secretas y patrióticas, 1913-1830”. REHMLAC 2, no. 2 (diciembre 2010-abril 2011 [citado el 23 de mayo de 2016]): disponible en http://revistas.ucr.ac.cr/index.php/rehmlac/article/view/6594/6285

Vázquez Semadeni, María Eugenia. "'He aquí los planes de la falsa filosofía contra la religión y el Estado'. La teoría de la conspiración masónica en Nueva España/México, 1738-1940”. Ponencia presentada en el IV Simposio Internacional de Historia de la Masonería y los Movimientos Asociativos Latinoamericanos y 
Caribeños: Prácticas asociativas y Modernidad, siglos XVIII - XXI. Universidad de Costa Rica, San José, 2015.

Velody, Irving y Williams, Robin. "Introduction". En The Politics of Constructionism. Editado por Irving Velody y Robin Williams. Londres, California y Nueva Delhi: Sage Publications, 1998.

Wright, Claire y Francisco Sánchez García. "Candidaturas independientes y desafección política: Actitudes ciudadanas en Nuevo León". En Panorama de la reforma electoral 2014 en México. Debates y análisis con experiencias desde el estado de Nuevo León. Coordinado por Gerardo Támez González y Xóchitl Arango Morales. Ciudad de México: Editorial Tirant Lo Blanch, 2016.

Zuñiga, Francisco. "Decepcionó a nuestras iglesias, asegura evangélica". Milenio, 30 de mayo de 2015. Citado el 2 de septiembre de 2016. http://www.milenio.com/politica/Decepciono-iglesias-aseguraevangelica $0 \quad 527347311$.html

\section{Anexo 1 \\ Transcripción Video 3}

Entrevistador 1. El día de hoy, licenciadazo [sic] Roberto Flores.

Entrevistador 1. Es uno de los masones de más alto grado en Nuevo León, el norte del país. Roberto Flores Treviño. Yo soy grado 33. Tengo cuatro grados 33 otorgados de cuatro diferentes grandes orientes del mundo Roberto Flores Treviño. Soy el representante legal del ingeniero Jaime Rodríguez Calderón. Entrevistador 1. Ahí está...

Roberto Flores Treviño. Como hermandad que es no tiene nada que ver con ninguna religión.

Roberto Flores Treviño. Es total y completamente espiritual la masonería, nada más. Científica y espiritual.

Roberto Flores Treviño. Para poder ser masón hay que creer en Dios, punto número uno. Punto número dos hay que tener libertad de pensamiento. Y entonces lo masones somos librepensadores.

Roberto Flores Treviño. Los cultos, los cultos y rituales religiosos no les gusta la gente librepensadora; le gusta la gente que no pregunta, la gente que única y exclusivamente cree, y al que única y exclusivamente cree se le llama borrego. Entonces, el que es borrego y sigue sin preguntar el porqué de las cosas, es lo que la gente de las iglesias y de los cultos religiosos necesita, el que no pregunte, porque si preguntas lo más probable es que no haya respuestas, y cuando no hay respuestas, entonces tienen que adjudicarle las cosas a la divinidad y a la deidad. 
Entrevistador 2. [Inaudible] Entonces ¿a qué se... a qué cree o considera usted que se deba que en ciertos círculos de la masonería tienen mala fama, como dijo el [Inaudible]? ¿Está satanizada...?

Roberto Flores Treviño. Pero no es en ciertos círculos. Vamos a decir las cosas como son: en todos los círculos.

Roberto Flores Treviño. Los cultos religiosos pretenden imponer su creencia. Te la inculcan y te prohíben que preguntes. Te prohíben que bajo ninguna circunstancia tú preguntes o cuestiones el fundamento de esto.

Entrevistador 2. ¿Y los masones lo cuestionan?

Roberto Flores Treviño. No necesariamente; ni siquiera nos metemos. Ni siquiera nos metemos. Ni siquiera les hacemos caso. Por ejemplo el otro día subieron ahí a la red unas fotografías en donde un caballero ponía ahí que los masones son... que son del diablo... que porque tienen un rito que... que este escupen y pisan la ostia, y que la ostia es un símbolo sagrado. Le escribí y le dije “¿de dónde sacas tu eso?” El fundamento; me encantaría que me dijeras en dónde está esa situación. Si te lo dijo tu abuelita, o te lo dijo una tía, pues eso es distinto. Pero ¿en dónde, de dónde sacas eso?

Entrevistador 2. [...] Que hay un círculo de masones que controlan a todos los demás masones. Que es como la élite de una logia que [inaudible], y que hacen que intervengan en la política...

Fin del video. 